\title{
On Dialactic Assessment of Professional Experience of Law Enforcement in the Field of Law Enforcement
}

\author{
Vladimir Valentinovich Kozhevnikov \\ Department of Theory and History of State and Law, Omsk State University Dostoevsky, Omsk, Russia \\ kta6973@rambler.ru
}

\section{Abstract}

This scientific article is devoted to the problem of professional experience of law enforcement in the law enforcement sphere. The author emphasizes that the latter is not only positive in nature, contributing to a quick and correct assessment, legal qualification of a particular situation, but also negative, causing professional deformation of the subjects of the application of law.
Keywords

professional experience; legal awareness application of law, legal practice; professional deformation

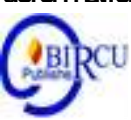

\section{Introduction}

It seems that the urgency of the problem of professional experience in law enforcement in the law enforcement sphere is determined by the need to ensure the effectiveness of this activity, which depends on a number of objective factors (the quality of the relevant legislation, the microclimate of the law enforcement team, the scientific organization of its employees, technical support, etc.) and, to a greater extent degree, from what is called the "human (humanitarian) factor", i.e. everything connected with a person.

\section{Research Methods}

When preparing a scientific article, the following methods were used: General Philosophical

General philosophical (dialectical-materialistic), which is used in all social sciences;

1. General scientific (analysis and synthesis, logical and historical, comparisons, abstractions, etc.), which are used not only by the theory of state and law, but also by other social sciences;

2. Special methods (philological, cybernetic, psychological, etc.), developed by special sciences and widely used for the knowledge of state and legal phenomena;

3. Private scientific (formal legal, interpretation of law, etc.), which are developed by the theory of state and law.

\section{Results and Discussion}

\subsection{The Ratio of Personal and Objective Legal Experience}

In our opinion, the concept of "professional experience" is secondary, derivative in relation to the concept of "experience" in general, which is associated with practically assimilated knowledge, sensations, perceptions, skills and abilities fixed in memory. Without going into detail in the philosophical, philological, psychological understanding of the concept of experience, which was the object of study by many famous scientists (Francis Bacon, Hugo Grotius, Georg Pucht, Friedrich Savigny, François Zhenis, 
Eliphas Levy, Lev Ivanovich Petrazhitsky, Maurice Oriou, Rudolf Iering, etc. .), we point out that two meanings of the term "professional legal experience" should be distinguished:

1) Personal experience of the relevant subject, which is expressed in certain legal knowledge, skills, habits, skill, etc., accumulated in the process of training, communication and practical legal activity.

2) Objective legal experience, which is formed in the course of one or another legal activity, in the process of distinguishing in legal actions and operations, means and methods, decisions made, the results of activities as more rational, progressive, correct, expedient, advanced, general and useful, which is important for the further improvement of specific legal activities, the process, which is formed in the process of resolving specific legal cases and generalizing the materials of legal practice. It seems that personal and objective professional legal experience are closely interrelated and complement each other, because the former is formed on the basis of a formulated objective professional legal experience, the content of which, in turn, is determined by the personal experience of the relevant law enforcement entities in the law enforcement sphere. We believe that the problem of professional experience in law enforcement is a psychological and legal problem, because, as noted by Alexander Ruvimovich Ratinov, “... the psychological aspects of legal consciousness play a conceptual role and are pivotal for legal psychology as a whole and its individual sections" [1].

It seems that turning to social psychology in the study of the legal consciousness of a person is quite natural and contributes to the enrichment of legal science. As the wellknown lawyer of pre-revolutionary Russia Dmitry Andreevich Dril rightly pointed out, law and psychology deal with the same phenomena - the laws of human social life, and therefore the law should borrow from psychology the means for studying consciousness [2]. Natalya Valerievna Shcherbakova, analyzing the legal setting as "a person's predisposition to perceiving the content of a rule of law, its assessment, readiness to commit an action, an act of legal significance, or as the likelihood of one or another variant of behavior (activity) in the field of legal regulation" [3], considering the first as the link that connects personality and law, legal feelings, motives, relations with social and legal activity, legal behavior, quite reasonably believes that "to understand such a transition requires a deep analysis of legal consciousness, its structure and functions and those social conditions in which legal consciousness is located. This problem should not be considered only within the framework of "pure law" [3].

Bearing in mind the second, legal aspect, the side of this phenomenon, it should be recognized that it is formed in the process of forming the professional consciousness of the law-enforcing subject, which objectively assumes that the subject has legal work experience. Indeed, one can agree with this, given that the law is not realized spontaneously, automatically, but with the active participation of its subjects, who have a certain set of relevant qualities.

\subsection{Professional Consciousness of Lawyers and Experience in the Application of Law}

It is not difficult to see that these scientists a priori associate the professional consciousness of lawyers with the experience of the application of law. Attempts to substantiate the position according to which professional legal consciousness is determined only by obtaining a higher legal education, in our opinion, do not stand up to criticism. We believe that graduates of law schools are carriers of an ordinary sense of justice, which is qualitatively different from the legal consciousness of first-year students. However, it should be emphasized that they are already beginning to form a professional sense of 
justice, which may or may not take shape, because this complex process is determined by a number of objective and subjective factors.

\subsection{The Psychological Aspect of Professional Legal Experience}

We believe that it is necessary to take into account the psychological aspect of the professional legal experience of the law enforcement entity. In psychological science, it is asserted that the properties (traits) of the personality are declared derivatives not only from interpersonal relations, but also from mental processes - "stable formations that provide a certain level of activity and behavior typical for a given person" [4]. They are also considered as elements of the psychological structure of the personality, combined, due to their huge number, in the corresponding structures, among which the greatest importance is given to the properties of temperament, social experience and personality orientation [5].

At one time, the German scientist Karl Joseph Anton Mittermeier in his work "The Doctrine of Proof", arguing the need for a psychological justification of judicial activity, wrote the following: criminal behavior, etc. " [6]. It seems that one should agree with Alexander Ruvimovich Ratinov, who reasonably emphasized that “... when solving complex cognitive problems, empirical experience is not enough. So, without serious psychological preparation, it is impossible to disclose and successfully investigate crimes of a non-obvious nature" [7].

We believe that poor psychological training is a chronic painful flaw in the professional activities of law enforcement officers. Lack of psychological training often prompts them to use force, violence, threats and other illegal measures. Considering psychological culture as a constituent component of the professional culture of a lawenforcing subject, we note that the first assumes that the relevant employees have a developed system of psychological knowledge, as well as skills and techniques that ensure a high culture of communication,

In modern conditions, a deep understanding is required that a special legal education without professional and psychological training is a hidden and dangerous defect that, in difficult situations of operational and official activity, can negate the legal training of an employee and lead to disruptions and mistakes. For example, very often it is psychological compatibility that contact with those who committed a crime, with witnesses or victims who are afraid to testify for any reason, in general with any person with whom an employee of the internal affairs bodies encounters in the course of his activities, can lead to success. ... In the literature, scientists reasonably argue about "psychological support for the implementation of legal norms" [8].

In our opinion, the professional face of a police officer in modern conditions is determined by his level of training in such areas as psychology and sociology, his ability to navigate in the field of interpersonal and family relations, communication skills, deep knowledge of all the subtleties of ethnic and racial problems, skills of artistic transformation into appropriate images for establishing and maintaining the necessary contacts with the population. Arguing about the professional beginning in the activities of the internal affairs bodies, Valery Vasilyevich Lazarev believes that it "presupposes special training, the assimilation of a certain set of knowledge, their constant renewal and deepening in close connection with practical transformative work" [9].

According to Yuri Igorevich Osipov, a generalized definition based on a variety of concepts existing in the American literature is the definition of professionalism in police work as a set of special knowledge and skills that allow the police to perform their inherent functions, including those associated with the use of physical coercion [10]. 


\subsection{Positive Characteristics of Professional Legal Experience}

On the one hand, the professional experience of law enforcement of employees of the internal affairs bodies, summarizing their legal knowledge, abilities, skills, etc., helps them navigate the evidentiary information, select from it everything necessary for the correct resolution of a particular legal case taking into account the requirements of the norms of substantive and procedural law. The positive side of this phenomenon is obvious. It facilitates and shortens the time it takes to make a decision. It seems that intuition, which is important in the disclosure and investigation of crimes, and which in the future must be backed up by an evidence base, should not be disregarded. Apparently, it is no coincidence that in the legal literature they note the fact that in no other profession is life experience so important, especially professional, as in the work of an investigator, other subjects of law enforcement [11].

\subsection{Negative Sides of Professional Legal Experience}

However, on the other hand, it should be borne in mind that, along with a positive role, the professional experience of law enforcement officers may have some negative sides. It should be borne in mind that the same type of legal situations, on which professional experience is oriented, generate, as a rule, stereotyping of intellectual processes, stereotyped actions and operations of these persons, which make it difficult to see the originality of a particular life case.

The literature draws attention to the fact that the law enforcement activity of most legal professions is distinguished by an extraordinary variety of tasks to be solved. Each new case for the subjects of law enforcement "represents a new task, and the less the template will be admitted by these persons, the more likely the correct outcome in the search for the truth" [12]. Indeed, in the course of his work, a lawyer has to deal with various life situations, the fates of different people. All this in aggregate and each situation separately, according to Ilya Isakovich Aminov, "requires an individual approach, a careful study of the legal relationship that has arisen." According to the author, "in order to assess certain actions in the most qualified and adequate way, to solve this or that issue, a lawyer, in addition to purely professional knowledge, needs extensive psychological knowledge" [13].

Thus, a survey of 300 investigators of the prosecutor's office and the Ministry of Internal Affairs showed that $18 \%$ of the respondents took actions not because they were dictated by the investigative situation, but because they had previously considered similar cases and undertaken similar actions; about $25 \%$ of respondents who have worked for more than 5 years said that they more often began to develop the habit of thinking and acting automatically in situations that have already been encountered in their practice. It is characteristic that $35 \%$ of investigators, when investigating cases with investigative errors, showed an accusatory bias, non-criticality, arrogance in assessing the case materials and making a decision, which is usually associated with the manifestation of professional deformation that occurs with increasing age and work experience, along with acquiring professional experience [14]. And although this study was carried out a long time ago, it seems that it has not lost its relevance for the present time.

Taking into account the positive in professional experience, one should agree with the idea of the need to have documents in the internal affairs bodies that summarize the work experience of employees of the internal affairs bodies, which would allow preserving this invaluable heritage for future generations. In this case, we are talking about the methodology for disclosing and investigating certain types of crimes, including a system of the most appropriate methods for organizing the disclosure and investigation of crimes, the 
use of tactics and scientific and technical means in specific conditions for the disclosure and investigation of certain types of crimes. We believe that the decisions of the Plenum of the Supreme Court of the Russian Federation on judicial practice in a certain category of criminal cases, which are an example of the correct and necessary understanding and application of law, are relevant for employees of internal affairs bodies from the point of view of improving their professional legal experience. Despite the fact that the introductory parts of the plenary sessions of the highest courts, called legal provisions, usually begin with the words: "based on the study of practice", "generalization of practice testifies", and such reasons as "lack of unity in understanding and application laws "," misunderstanding, interpretation of laws ", etc., these circumstances do not exclude the recognition of legal provisions of law-making significance [15].

It seems that in the internal affairs bodies it is necessary to revive the institution of mentoring, which allows maintaining the continuity of professional experience in law enforcement.

\subsection{Professional Deformation of Practicing Lawyers}

At the same time, one should take into account its negative consequences professional deformation, the danger of which lies not so much in itself as in relation to it. Knowledge of the phenomenon in question and, in connection with this, a critical attitude to the assessment of their decisions and actions can warn practical workers of the internal affairs bodies against wrong actions. On the contrary, the lack of criticality, arrogance and complacency, forgetting that every legal case is individual, the manifestation of a sense of omniscience and hence infallibility can lead to an accusatory bias and cause serious errors in the law enforcement process. Professional deformation is a negative socio-psychological phenomenon that appears in the form of a variety of personal behavioral manifestations that have a destructive effect on the process and result of professional activity. This is a condition in which a person transfers the images of a certain group of people to everyone, for example, a doctor begins to consider all people sick, a warden - prisoners, an investigator - criminals (suspects). This is just one of the manifestations of professional deformation. Professional deformation affects the decrease in empathy (from the word "empathy" as understanding the feelings of other people and the willingness to provide emotional support; this is the ability to put oneself in the place of another person (or object), the ability to empathize, the ability to perceive the inner world of another accurately while maintaining emotional and semantic shades) personality traits callousness appears, unwillingness to take someone else's pain upon oneself, lack of mercy and humanity, unwillingness and inability to understand another person; there is a reluctance to communicate, tact decreases, rudeness appears; reduced responsibility. For example, when a murder is committed by employees of the internal affairs bodies, the following question comes to the fore: was the act committed in conditions of obvious or non-obviousness?

As Marat Iskhakovich Yenikeev wrote, "the powers of an investigator can cause and consolidate such negative personal qualities as arrogance, arrogance, rudeness, mental callousness. Constant subordination of the investigator's activities to procedural regulation can contribute to rigidity (i.e., difficulty or impossibility of changing the program of activities in situations requiring its restructuring - Vladimir Valentinovich Kozhevnikov), inflexibility, adherence to stereotyped decisions, formalism; constant contact with asocial manifestations - to form a stable suspicion, bias, a tendency to an accusatory bias in their activities. Frequent lack of time can lead to haste, superficiality, disregard for individual procedural requirements. These possible manifestations of personal and professional 
deformation should be removed by the developed stable self-control of the investigator "[16].

At the same time, we emphasize that the professional deformation of law enforcement subjects of the internal affairs bodies in various forms of its manifestation objectively determines not only negative legal, but also non-legal consequences, in particular, a low assessment by the population of the activities of the relevant law enforcement agencies. Thus, the Federal State Budgetary Institution VNII of the Ministry of Internal Affairs of Russia in the 2nd and 4th quarters of 2016 measured public opinion in 85 constituent entities of the Federation on the activities of the police (94 thousand Russians). As a result of this sociological study, it turned out that in $201647 \%$ of Russians express confidence in the police officers of their region (in $2015-46 \%$ ), but the other half of citizens $(47 \%)$ still mistrust the police. Some of the citizens surveyed had to deal with one or another illegal actions of police officers: every tenth was a witness of rude and tactless treatment $(11 \%)$, the use of official position for personal purposes $(8 \%)$; there are cases of distortion of facts (7\%), bribes (6\%), etc. [17]. And although research has been done in the past, it seems that the situation has changed little. On October 26, 2020, an allRussian poll "VTsIOM-Sputnik" was conducted (a poll of 1,600 Russians under the age of 18), which showed that only almost $60 \%$ of respondents trust police officers. $41 \%$ assess their activities positively, $41 \%$ give an average assessment and 14\% - negative [18].

\section{Conclusion}

As a result of the study, it can be concluded that the professional experience of law enforcement of employees of internal affairs bodies in the law enforcement sphere, formed in the process of upbringing, education and practical activity and generalizing the relevant professional knowledge, skills, skills, etc. on the one hand, it helps them to navigate the evidential information, to select from it everything necessary for the correct resolution of a particular legal case, taking into account the requirements of the norms of substantive and procedural law, however, on the other hand, it should be borne in mind that the same type of legal situations on which professional experience is guided, generate, as a rule, stereotyping of intellectual processes, routine actions and operations of these persons, making it difficult to see the originality of a particular life case, lack of criticality, arrogance and complacency, oblivion of the fact that every law the case is individual, the manifestation of a sense of omniscience and hence their infallibility can lead to an accusatory bias and cause serious errors in the process of law enforcement in this area.

\section{References}

[1]. Patinov Alexander Ruvimovich. Forensic psychology as a science // Legal psychology: a reader / comp. Vladimir Vladimirovich. Romanov, Elena Vladimirovna. Romanov. M .: Jurist, 2000.P. 20.

[2]. Dril Dmitry Andreevich. Crime and criminals: (Criminal psychological studies). Saint Petersburg: Yakov Abramovich Kantorovich Publishing House, 1895. P. 16.

[3]. Shcherbakova Natalia Valerievna. Legal attitude and social activity of the individual. M.: Jurid. lit-ra, 1986. P. 17.

[4]. Kovalev Alexander Grigorievich. Psychology of Personality. Moscow: Education, 1970. P. 25.

[5]. Social psychology. A short sketch / under the general ed. German Pavlovich Predvochny and Yuri Alexandrovich Sherkovin. M .: Politizdat, 1975.Pp. 39-40. 
[6]. Boltunov Alexander Pavlovich. On forensic psychology // Legal psychology: a reader / comp. Vladimir Vladimirovich. Romanov, Elena Vladimirovna Romanova. M .: Jurist, 2000.P. 33.

[7] .Ratinov Alexander Ruvimovich. Forensic psychology for investigators. M .: Jurlitinform, 2001.P. 3.

[8]. Shikhantsov Gennady Grigorievich. Legal psychology: textbook. M : Zertsalo, 1998.P. 59.

[9]. Lazarev Valery Vasilievich. Theoretical issues of the relationship between professional and social principles in the activities of internal affairs bodies // Lazarev Valery Vasilievich. Elected. works in 3 volumes. Vol. 1. Law. Legality. Application of the law. M .: New Justice, 2010.P.606.

[10]. Osipov Yuri Igorevich. Problems of professionalism in the activities of the US police: theory and practice // Professional and social principles in the activities of internal affairs bodies: history and modernity. M : Academy of the Ministry of Internal Affairs of the USSR, 1990.Pp. 140-144.

[11]. Baskov Vladimir Ivanovich. On the preliminary investigation // Sov. Justice. 1990. No. 15. P.16.

[12]. Chufarovsky Yuri Valentinovich. Legal psychology in questions and answers: a tutorial. M .: Prospect, 2010. P.86.

[13]. Aminov Ilya Isakovich. Psychology of the activity of a lawyer: a textbook. M .: UNITY-DANA, 2009.P. 19.

[14]. Dubrivny Vladlen Alexandrovich. The activities of an investigator to investigate crimes. Saratov: Saratov University, 1989. P. 94.

[15]. Chervonyuk Vladimir Ivanovich. Theory of state and law: textbook. M .: INFRA-M, 2006.P. 548.

[16]. Enikeev Marat Iskhakovich. Legal psychology: textbook. M .: Norma, 2000.P. 21.

[17]. Public opinion. Ministry of Internal Affairs in the regions. Ministry of Internal Affairs. RF Public opinion (Date of treatment - 27.10 17).

[18] VTsIOM: more than half of Russians trust their employees ... // https://tass.ru/obschestvo/9958633 (Date of access: 28.03.21). 